\title{
Dynamic Compression Promotes the Matrix Synthesis of Nucleus Pulposus Cells Through Up-Regulating N-CDH Expression in a Perfusion Bioreactor Culture
}

\author{
Yichun Xua Hui Yao ${ }^{a}$ Pei Lib,c Wenbin Xua Junbin Zhang ${ }^{a} \quad$ Lulu Lva $^{\mathrm{a}}$ \\ Haijun Teng ${ }^{b}$ Zhiliang Guo ${ }^{b}$ Huiqing Zhao ${ }^{a}$ Gang Hou
}

\begin{abstract}
aDepartment of Orthopaedics, The Third Affiliated Hospital of Sun Yat-sen University, Guangzhou, ${ }^{b}$ Department of Orthopaedics, No. 89 hospital of PLA, Weifang, Shandong, 'Department of Orthopaedics, Southwest Hospital, Third Military Medical University, Chongqing, China
\end{abstract}

\section{Key Words}

Nucleus pulposus $\cdot$ Dynamic $\cdot$ Static $\cdot$ Compression $\cdot$ Matrix $・$ Regeneration

\begin{abstract}
Background/Aims: An adequate matrix production of nucleus pulposus (NP) cells is an important tissue engineering-based strategy to regenerate degenerative discs. Here, we mainly aimed to investigate the effects and mechanism of mechanical compression (i.e., static compression vs. dynamic compression) on the matrix synthesis of three-dimensional (3D) cultured NP cells in vitro. Methods: Rat NP cells seeded on small intestinal submucosa (SIS) cryogel scaffolds were cultured in the chambers of a self-developed, mechanically active bioreactor for 10 days. Meanwhile, the NP cells were subjected to compression (static compression or dynamic compression at a $10 \%$ scaffold deformation) for 6 hours once per day. Unloaded NP cells were used as controls. The cellular phenotype and matrix biosynthesis of NP cells were investigated by real-time PCR and Western blotting assays. Lentivirus-mediated $\mathrm{N}$-cadherin (N-CDH) knockdown and an inhibitor, LY294002, were used to further investigate the role of $\mathrm{N}-\mathrm{CDH}$ and the PI3K/Akt pathway in this process. Results: Dynamic compression better maintained the expression of cell-specific markers (keratin-19, FOXF1 and PAX1) and matrix macromolecules (aggrecan and collagen II), as well as $\mathrm{N}-\mathrm{CDH}$ expression and the activity of the PI3K/Akt pathway, in the 3D-cultured NP cells compared with those expression levels and activity in the cells grown under static compression. Further analysis showed that the N-CDH knockdown significantly down-regulated the expression of NP cell-specific markers and matrix macromolecules and inhibited the activation of the PI3K/Akt pathway under dynamic compression. However, inhibition of the PI3K/Akt pathway had no effects on $\mathrm{N}-\mathrm{CDH}$ expression but down-regulated the expression of NP cell-specific markers and matrix macromolecules under dynamic compression. Conclusion: Dynamic compression increases the matrix synthesis of 3D-cultured NP cells compared with that of the cells under static
\end{abstract}

Y. Xu, H. Yao and P. Li contributed equally to this work

Huiqing Zhao

and Gang Hou

KARGER
Department of Orthopaedics,

The Third Affiliated Hospital of Sun Yat-sen University (China)

E-Mail robinham1234@163.com; 18929588445@189.cn 


\section{Cellular Physiology Cell Physiol Biochem 2018;46:482-491 \\ \begin{tabular}{l|l} 
DOI: 10.1159/000488616 & and Biochemistry \\
Published online: April 03, 2018 & $\begin{array}{l}\text { 2018 The Author(s). Published by S. Karger AG, Basel } \\
\text { www.karger.com/cpb }\end{array}$
\end{tabular} \\ Xu et al.: Dynamic Compression Promotes the Matrix Synthesis of NP Cells}

compression, and the $\mathrm{N}-\mathrm{CDH}-\mathrm{PI} 3 \mathrm{~K} / \mathrm{Akt}$ pathway is involved in this regulatory process. This study provides a promising strategy to promote the matrix deposition of tissue-engineered NP tissue in vitro prior to clinical transplantation.

\section{Introduction}

Intervertebral disc degeneration (IDD) is a progressive condition which leads to functional deficiency in patients [1-4]. Existing therapies including spinal fusion and discectomy are mainly aimed to alleviate pain symptoms but not to biologically regenerate disc function. Currently, considerable efforts have been made toward biologically regenerating degenerative discs using tissue engineering approaches [5-9].

The intervertebral disc (IVD) is a cartilaginous structure consisting of the nucleus pulposus (NP), annulus fibrosus (AF) and cartilage endplate (CEP) [10]. IVDs play an important role in load bearing, absorption and transmission between two adjacent vertebral bones [11], which mainly depends on the matrix homeostasis within the NP region. IDD is proposed to originate in the NP region, which is characterized by a decrease in the NP cell density and normal extracellular matrix content (i.e., proteoglycan and collagen II) [12, 13]. All these cellular and molecular changes can lead to NP dehydration and thus weaken the disc capacity to absorb compression [14]. Based on the previous understanding of disc degeneration pathogenesis, a widely acceptable consensus has been reached that increasing the quantity and enhancing the biosynthesis of NP cells encapsulated in a biocompatible scaffold are important to regenerate discs using a tissue engineering approach $[1,15,16]$.

Under physiological conditions, the disc NP cells are subjected to various kinds of mechanical compression [17], which have a great influence on disc NP cell biology, including cell phenotype and matrix biosynthesis [18-21]. Among the types of mechanical loads, static compression and dynamic compression have usually been applied in the research field of disc degeneration [22-24]. Though a general consensus has been reached that dynamic compression is more physiologically relevant than static compression in vivo [24] and that static compression often causes negative effects on healthy disc biology compared with those in dynamic compression [23], the potential mechanisms need to be further studied. $\mathrm{N}$-cadherin $(\mathrm{N}-\mathrm{CDH})$ is one of the classical cadherin transmembrane glycoproteins [25]. It was first identified in the neural system and is responsible for the development of the neural crest and the formation of neuronal connections [25, 26]. Furthermore, N-CDH is highly expressed in normal disc NP cells compared with the expression in degenerative NP cells, adjacent disc AF cells and CEP cells [27, 28]. In addition, N-CDH-mediated signaling is helpful to maintain the normal NP cell phenotype and NP matrix synthesis in vitro [2932]. However, whether N-CDH-mediated signaling is responsible for the positive effects of dynamic compression on NP cell biology remains unknown.

In this study, we hypothesize that dynamic compression may enhance NP matrix biosynthesis and maintain the NP cell phenotype through N-CDH-mediated signaling. The main objective of this study is to compare the effects of static and dynamic compression on the matrix synthesis of three-dimensional (3D) cultured NP cells in vitro using a selfdeveloped perfusion bioreactor and to investigate the role and underlying mechanism of $\mathrm{N}-\mathrm{CDH}$ in regulating this process.

\section{Materials and Methods}

Ethical statement

All experiments in this study were approved by the Ethics Committee at the Third Affiliated Hospital of Sun Yat-sen University and were performed in accordance with the relevant guidelines [SYMN (YUE) 2009-0014]. 


\section{Cellular Physiology Cell Physiol Biochem 2018;46:482-491

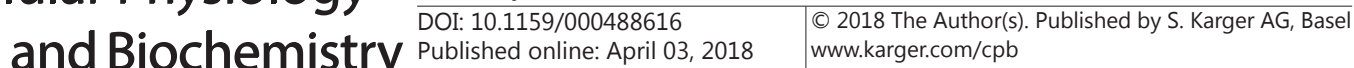 \\ Xu et al.: Dynamic Compression Promotes the Matrix Synthesis of NP Cells}

\section{Rat NP cell isolation and culture}

Thirteen healthy Sprague-Dawley rats (male, 230-250 g and 6-8 weeks old) were used in this study. Briefly, after the thoracic and lumbar discs were collected, the innermost NP tissue was separated under a dissecting microscope. Next, the tissue was subjected to enzymatic digestion with $0.25 \%$ trypsin (Gibco, USA) for 2-3 minutes followed by $0.25 \%$ Type I collagenase (Sigma, USA) for 8-10 minutes. All collected NP cell pellets were re-suspended in a monolayer culture with DMEM/F12 medium (HyClone, USA) containing $10 \%(\mathrm{v} / \mathrm{v})$ fetal bovine serum (FBS, Gibco, USA) and 1\% (v/v) penicillin-streptomycin (Gibco, USA). Culture medium was refreshed every two days.

\section{NP cell transfection}

The recombinant lentiviral vector LV3-N-CDH (Genepharma, Shanghai, China) was used to silence $\mathrm{N}-\mathrm{CDH}$ expression in NP cells (NP-shN-CDH). NP cells transfected with the negative vector (LV3-N-CDHNC) were used as controls (NP-shN-CDH-NC). According to the manufacturer's instructions, the transfected cells were further selected via puromycin. Transfection efficacy was verified by real-time polymerase chain reaction (PCR) and Western blotting assays.

\section{NP cell seeding and compressive loading application}

NP cells $\left(5 \times 10^{6}\right.$ cells per scaffold, $\left.500 \mu \mathrm{L}\right)$ were seeded onto a lyophilized porcine small intestinal submucosa (SIS) cryogel. The SIS cryogel was freely provided by Dr. Wenping Wang (Department of Cosmetic Plastic Surgery, Southwest Hospital, Third Military Medical University). After each cell-seeded scaffold was pre-cultured for 3 days in an incubator $\left(37^{\circ} \mathrm{C}, 5 \% \mathrm{CO}_{2}\right)$, the scaffolds were put into a culture chamber of a self-developed perfusion bioreactor and further bioreactor-cultured for 10 days. The NP cells seeded on scaffolds were assigned into the following groups: the control group (non-compression), the static compression group ( $10 \%$ deformation for 6 hours per day) and the dynamic compression group $(10 \%$ deformation compression at a frequency of $1.0 \mathrm{~Hz}$ for 6 hours per day). The culture medium was circulated at $15 \mathrm{~mL} / \mathrm{min}$ and changed every 3 days.

\section{Cytocompatibility test of the scaffold}

To evaluate the cytocompatibility of the SIS cryogel, we tested NP cell proliferation and viability when the cells were seeded onto the SIS cryogels. The sterilized SIS cryogel was made into a cylinder-like formation $\left(7 \mathrm{~mm}\right.$ in diameter and $5 \mathrm{~mm}$ in height) using a homemade mold. Then, NP cells $\left(1 \times 10^{6}\right.$ cells per scaffold, $500 \mu \mathrm{L}$ ) were seeded onto the SIS cryogel as described. Next, the cell-seeded SIS cryogels were placed in an incubator $\left(37^{\circ} \mathrm{C}, 5 \% \mathrm{CO}_{2}\right)$ for 3 hours to allow for cell adhesion. NP cell proliferation potency was determined using a Cell Counting Kit-8 (CCK-8, Beyotime, China). Briefly, on days 1, 3, 5 and 7, the CCK-8 working solution was added into the fresh culture medium, and then incubated for another 2 hours. Then, $200 \mu \mathrm{L}$ of reaction mixture was used to analyze the cell proliferation potency, which was reflected by the absorbance value at a wavelength of $450 \mathrm{~nm}$ that was measured using a microplate reader (Model 550, Bio-Rad, USA).

NP cell viability was analyzed using a LIVE/DEAD Viability/Cytotoxicity ${ }^{\circledR}$ Kit (Invitrogen, USA) according to the manufacturer's instructions. Briefly, on days 3 and 7, a SIS cryogel slice was prepared using a homemade tool and washed with PBS 2-3 times. Then, NP cells on the scaffolds were stained with $2 \mu \mathrm{M}$ calcein green (green fluorescence when metabolized by live cells, $495 \mathrm{~nm} / 515 \mathrm{~nm}$ excitation/emission) and $4 \mu \mathrm{M}$ ethidium homodimer (red fluorescence when metabolized by dead cells, $495 \mathrm{~nm} / 635 \mathrm{~nm}$ excitation/ emission) for 40 minutes at room temperature. Finally, the live or dead NP cells were viewed under a laser scanning confocal microscope (LSCM; Carl Zeiss, LSM 780, Germany).

Table 1. Primers of target genes

Real-time PCR analysis

Briefly, total RNA was extracted using the TriPure Isolation Reagent (Roche) and synthesized into cDNA with a reverse transcription

\begin{tabular}{cccc}
\hline Gene & Accession number & Forward (5'-3') & Reverse (5'-3') \\
\hline $\begin{array}{c}\text { B-actin } \\
\text { Aggrecan }\end{array}$ & NM_031144.3 & CCGCGAGTACAACCTTCTTG & TGACCCATACCCACCATCAC \\
Collagen II & NM_012929.1 & GCCAGGATGCCCGAAAATTAG & CCAGCCTTCTCGTCAAATCCT \\
Keratin-19 & NM_199498.2 & ATGAGCTGAACACCCAGGTC & ATGCTGAGCTGAGACTGCAA \\
FOXF1 & XM_006255724.3 & CGCTCAGCGAGATCTACCA & GGGCAGTTTGATGAAGCACT \\
PAX1 & NM_001107787.1 & GACTCGAGAAACCTGCCTTG & ATACTCCGTGCTGGTTGGAA \\
\hline
\end{tabular}




\section{Cellular Physiology Cell Physiol Biochem 2018;46:482-491 and Biochemistry Published online: April 03, $2018 \quad$\begin{tabular}{l|l} 
DOI: 10.1159/000488616 2018 The Author(s). Published by S. Karger AG, Basel \\
www.karger.com/cpb
\end{tabular} \\ Xu et al.: Dynamic Compression Promotes the Matrix Synthesis of NP Cells}

kit (Roche). Then, cDNA, primers and SYBR Green Mix (Dongsheng Biotech, China) were mixed together and loaded into a real-time PCR instrument (CFX96 Real-Time System, Bio-Rad). Primers of the target genes are shown in Table 1. $\beta$-actin was used as the reference gene, and the relative gene expression was calculated as $2^{-\Delta \Delta \mathrm{Ct}}$.

\section{Western blotting assay}

Briefly, the cell-scaffold constructs were cut into small pieces $(1 \mathrm{~mm} \times 1 \mathrm{~mm} \times 1 \mathrm{~mm})$. Then, total protein was extracted from the cellular component using a RIPA reagent (Beyotime, China), and protein concentration was measured using a protein BCA detection kit (Beyotime, China). Protein samples in each group were subjected to SDS-PAGE and transferred to PVDF membranes. Then, incubation with primary antibodies ( $\beta$-actin: Proteintech, 60008-1-Ig; N-CDH: Abcam, ab18203; aggrecan: Santa Cruz, sc-16492; collagen II: Abcam, ab34712; Akt: Cell Signaling Technology, \#9272; p-Akt: Cell Signaling Technology, \#9271; all diluted 1:1000) and corresponding HRP-conjugated secondary antibodies was performed. Finally, protein bands on the PVDF membranes were visualized using the SuperSignal West Pico Trial Kit (Thermo, USA). Protein expression normalized to $\beta$-actin was analyzed using ImageJ software (National Institutes of Health, USA).

\section{Statistics}

All numerical data expressed as the mean \pm SD were analyzed using SPSS version 13.0 software in this study. Each experiment in this work was performed in triplicate. After homogeneity testing for variance was completed, one-way analysis of variance (ANOVA) was performed and then post hoc LSD tests were carried out. A significant difference was indicated when $p$-value $<0.05$.

\section{Results}

\section{Cytocompatibility test}

Though previous studies have demonstrated that this SIS cryogel has good biocompatibility, we still simply evaluated the cytotoxicity of the SIS cryogel here. The results showed that NP cells could normally proliferate in the SIS cryogel, which was indicated by an increase in the OD value at $450 \mathrm{~nm}$ with increasing experiment duration (Fig. 1A). Then, we evaluated the cell viability of NP cells seeded on the scaffold. The results showed that almost all NP cells were stained with green fluorescence and few NP cells were stained with red fluorescence, suggesting that the NP cells can remain viable in the SIS cryogel (Fig. 1B).

Dynamic compression up-regulated gene expression of NP cell-specific markers compared with those in the static compression condition

The maintenance of a normal cell phenotype is important in constructing an engineered tissue. Previous studies have demonstrated that keratin-19, FOXF1 and PAX1 are three cellular markers of normal NP cells [33-35]. In this study, the results showed that the mRNA expression of keratin-19, FOXF1 and PAX1 in the dynamic compression group was higher than that in the static compression and control groups, and static compression significantly down-regulated the expression of FOXF1 and PAX1 compared with that in the control group (Fig. 2).

Dynamic compression
increased NP matrix
biosynthesis compared
with that in the static
compression condition
Because the main matrix
protein molecules within

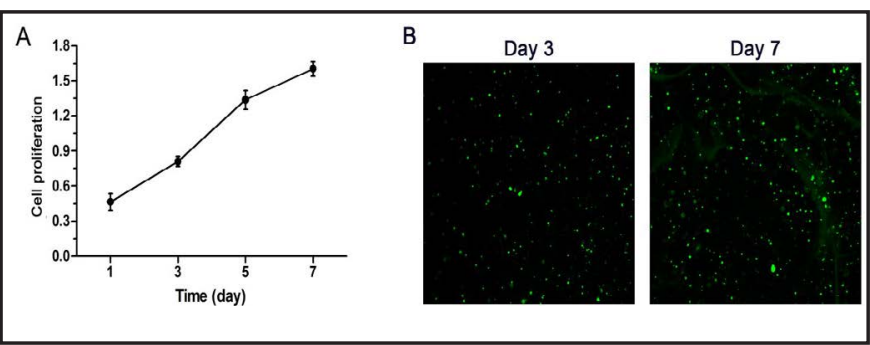

Fig. 1. Cytocompatibility evaluation of the small intestinal submucosa (SIS) cryogel. A: Cell proliferation of the nucleus pulposus (NP) cells encapsulated in the SIS cryogel. B: Cell viability of the NP cells encapsulated in the SIS cryogel by LIVE/ DEAD staining. All numerical data are expressed as the mean \pm SD $(n=3)$. 
the natural NP tissue are aggrecan and collagen II [36], the expression of NP matrixrelated macromolecules was investigated. Here, we found that dynamic compression significantly up-regulated the gene expression of aggrecan and collagen II compared with that in the static compression and control groups (Fig. 3A). Consistently, the protein expression of aggrecan and collagen II in the dynamic compression group was increased compared with that in the static compression and control groups (Fig. 3B). Dynamic compression
increased N-CDH expression
and the activity of the PI3K/
Akt pathway compared with
the expression and activity
in the static compression
group
As an important molecule that is helpful to maintain a normal NP cell phenotype and NP matrix synthesis in vitro [29], results showed that $\mathrm{N}-\mathrm{CDH}$ expression in the dynamic compression group was increased both at gene and protein levels compared with those in the static compression group and the control group

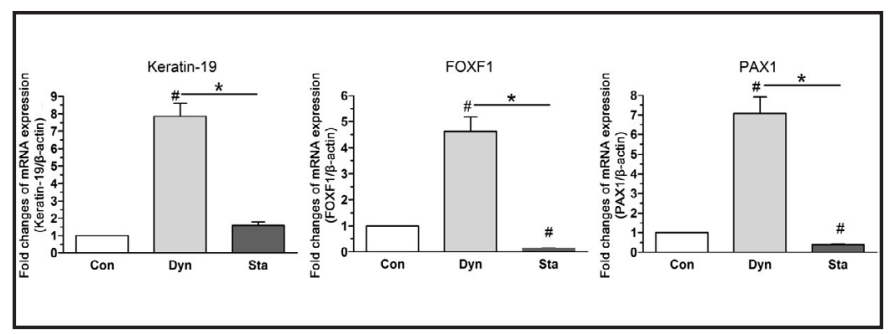

Fig. 2. Dynamic compression up-regulated the gene expression of nucleus pulposus (NP) cell-specific markers compared with that in the static compression group. Gene expression of keratin-19, FOXF1 and PAX1 was analyzed by real-time PCR. All data are expressed as the mean \pm SD $(n=3)$. *: Indicates a significant difference $(\mathrm{p}<0.05)$ between two groups; \#: indicates a significant difference $(p<0.05)$ compared with the control group.

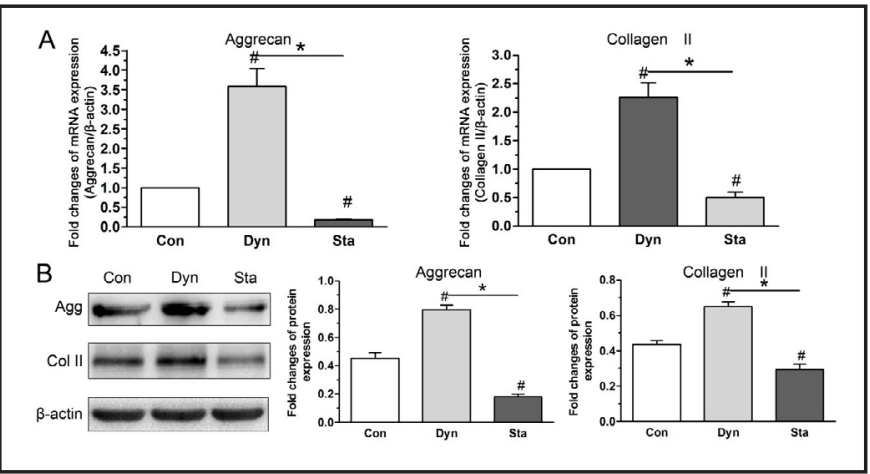

Fig. 3. Dynamic compression increased the matrix biosynthesis compared with that under static compression in nucleus pulposus (NP) cells encapsulated in the small intestinal submucosa (SIS) cryogel. A: Real-time PCR analysis of the mRNA expression of aggrecan and collagen II in NP cells. B: Western blotting analysis of the protein expression of aggrecan and collagen II in NP cells. All data are expressed as the mean \pm SD $(n=3)$. *: Indicates a significant difference $(\mathrm{p}<0.05)$ between two groups; \#: indicates a significant difference $(\mathrm{p}<0.05)$ compared with the control group.

Fig. 4. Dynamic compression increased $\mathrm{N}$-cadherin $(\mathrm{N}-\mathrm{CDH})$ expression and the activity of the PI3K/Akt pathway compared with the expression and activity under static compression in nucleus pulposus (NP) cells encapsulated in the small intestinal submucosa (SIS) cryogel. A: Real-time PCR and Western blotting analysis of N-CDH expression, respectively. B: Western blotting analysis of the activation of the PI3K/Akt pathway. All data are expressed as the mean \pm SD

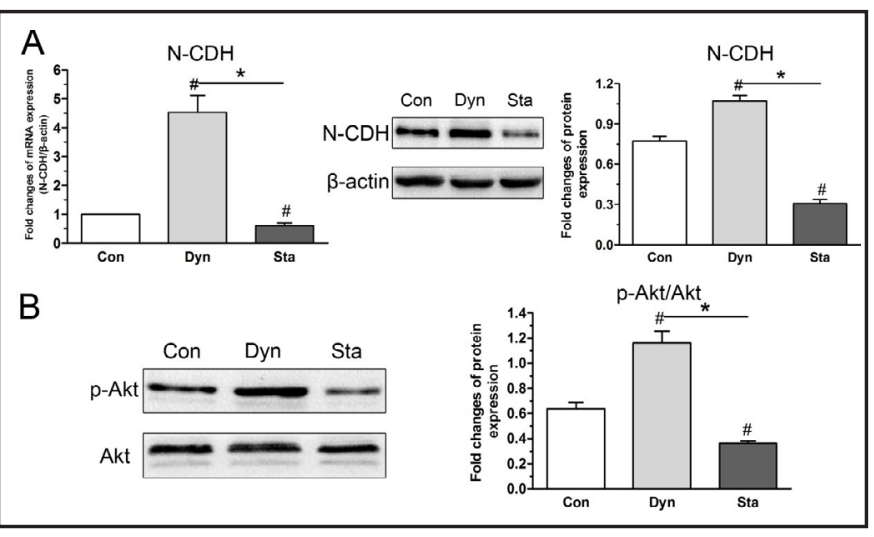
$(\mathrm{n}=3) . \quad *$ : Indicates a significant difference $(p<0.05)$ between two groups; \#: indicates a significant difference $(p<0.05)$ compared with the control group. 
(Fig. 4A). Moreover, N-CDH expression in the static compression group was lower than that in the control group. In addition, the activity of the PI3K/Akt pathway showed a similar trend among these groups (Fig. 4B).

\section{$\mathrm{N}-\mathrm{CDH} \quad$ knockdown attenuated the activation of the PI3K/} Akt pathway, NP cell phenotype and matrix biosynthesis under dynamic compression

To investigate whether $\mathrm{N}-\mathrm{CDH}$ up-regulation is responsible for the maintenance of the normal NP cell phenotype and NP matrix biosynthesis under dynamic compression, $\mathrm{N}-\mathrm{CDH}$ expression was silenced using recombinant lentiviral vectors (Fig. 5). Subsequently, we found that the N-CDH knockdown inhibited the activation of the PI3K/Akt pathway and decreased $\mathrm{N}-\mathrm{CDH}$ expression under dynamic compression (Fig. 6A). Additionally, the N-CDH knockdown decreased mRNA expression of NP cell-specific markers (keratin-19, FOXF1 and PAX1) (Fig. 6B) and suppressed the protein expression of the NP matrix macromolecules (aggrecan and collagen II) under dynamic compression (Fig. 6C).

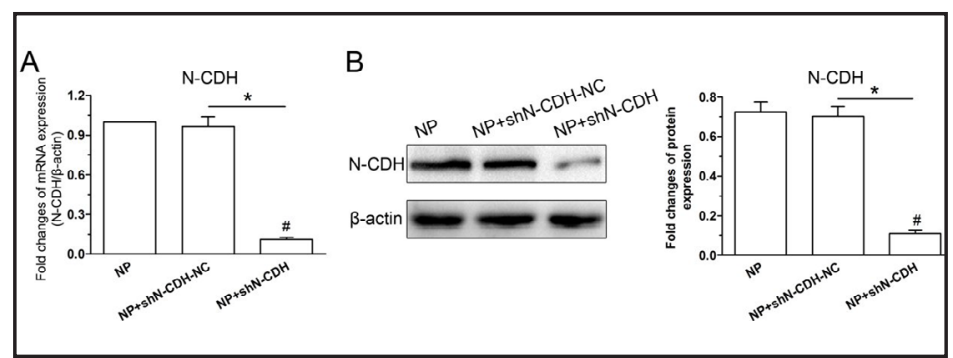

Fig. 5. Verification of $\mathrm{N}$-cadherin $(\mathrm{N}-\mathrm{CDH})$ knockdown in nucleus pulposus (NP) cells. A: Real-time PCR analysis of $\mathrm{N}-\mathrm{CDH}$ gene expression. B: Western blotting analysis of N-CDH protein expression.

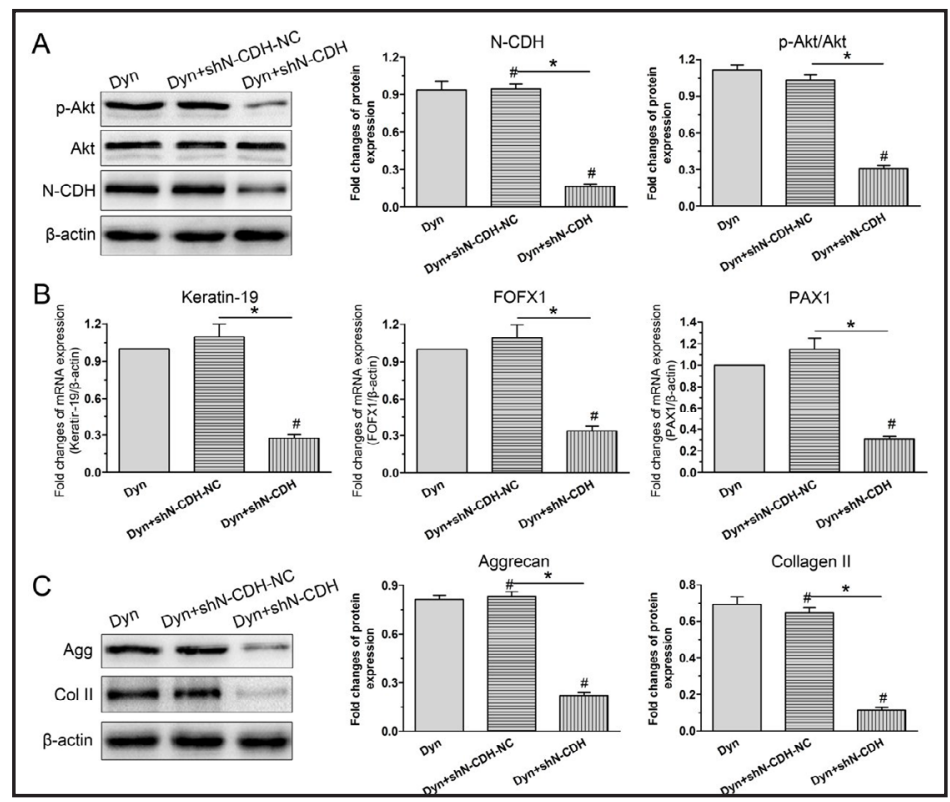

Fig. 6. $\mathrm{N}$-cadherin $(\mathrm{N}-\mathrm{CDH})$ knockdown attenuated the activation of the PI3K/Akt pathway, NP cell phenotype and matrix biosynthesis of nucleus pulposus (NP) cells encapsulated in the SIS cryogel under dynamic compression. A: Western blotting analysis of the expression of N-CDH and the activity of the PI3K/Akt pathway under dynamic compression after N-CDH knockdown in NP cells. B: Real-time PCR analysis of the expression of NP cell-specific markers (keratin-19, FOXF1 and PAX1) under dynamic compression after N-CDH knockdown in NP cells. C: Western blotting analysis of the expression of NP matrix macromolecules (aggrecan and collagen II) under dynamic compression after N-CDH knockdown in NP cells. All data are expressed as the mean $\pm S D(n=3)$. *: Indicates a significant difference $(\mathrm{p}<0.05)$ between two groups; \#: indicates a significant difference $(p<0.05)$ compared with the control NP cells or the Dyn group.

Inhibition of the PI3K/

Akt pathway attenuated matrix biosynthesis and NP cell phenotype under dynamic compression

To further investigate the role of the PI3K/Akt pathway and determine the relationship between N-CDH and the PI3K/Akt pathway, we used the inhibitor LY294002 $(10 \mu \mathrm{M})$ to inhibit the activation of the PI3K/Akt pathway in NP cells under dynamic compression (Fig. 7A). The results showed that the inhibitor had no effects on N-CDH expression in NP cells under 
dynamic compression, but it significantly down-regulated the protein expression of NP matrix macromolecules (aggrecan and collagen II; Fig. 7B) and decreased the gene expression of NP cellspecific makers (keratin-19, FOXF1 and PAX1; Fig. 7C) under dynamic compression.

\section{Discussion}

Intervertebral disc degeneration is a disease that is positively correlated with aging $[37,38]$. With the increase in the population of elderly people around the world, disc degeneration has attracted more and more attention [39]. Traditional surgical treatments are able to alleviate pain symptoms in most instances but are not able to biologically restore normal disc functions. It is well established that

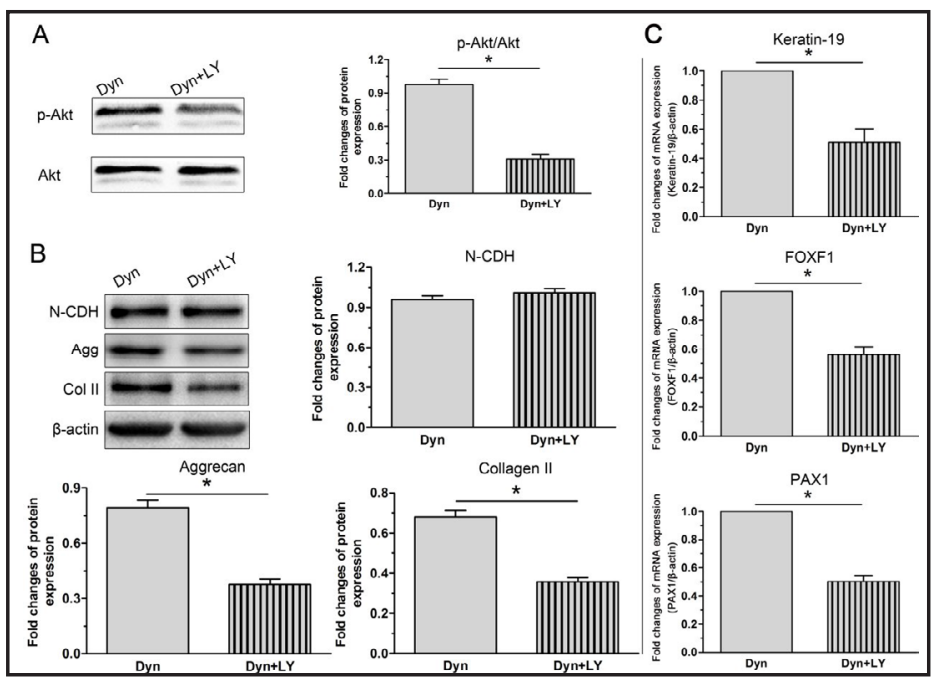

Fig. 7. Inhibition of the PI3K/Akt pathway attenuated the matrix biosynthesis and NP cell phenotype but had no effects on N-cadherin (N-CDH) expression in nucleus pulposus (NP) cells under dynamic compression. A: Verification of the inhibitory effect of LY294002 on PI3K/Akt pathway activation. B: Western blotting analysis of the expression of N-CDH and NP matrix macromolecules (aggrecan and collagen II) under dynamic compression after inhibiting the PI3K/Akt pathway. C: Real-time PCR analysis of the expression of NP cell-specific markers (keratin-19, FOXF1 and PAX1) under dynamic compression after inhibiting the PI3K/Akt pathway. All data are expressed as the mean $\pm S D(n=3)$. *: Indicates a significant difference $(\mathrm{p}<0.05)$ between two groups. biological therapies for disc degeneration are better able to restore normal disc function than previous traditional treatments [2]. Importantly, the normal biological function of NP cells (i.e., matrix biosynthesis) is important for the efficacy of the tissue-engineered NP tissue in regenerating disc degeneration [40]. In the present study, we demonstrated that dynamic compression is more beneficial than static compression to increase the matrix synthesis of NP cells and that the $\mathrm{N}-\mathrm{CDH}-\mathrm{PI} 3 \mathrm{~K} /$ Akt pathway is involved in this regulatory process.

Degenerative discs often have a limited number of viable cells, which directly contributes to the decrease in normal disc NP matrix components and results in attenuated disc function [41]. During the past decades, various kinds of cell sources were adopted in constructing cell-based scaffolds to regenerate degenerative discs, such as autologous or xenogenous NP cells and mesenchymal stem cells (MSCs) $[42,43]$. Apart from the cell source, superior biocompatibility is another necessary requirement for cell-based scaffolds to regenerate degenerative discs. In this study, we evaluated the cytotoxicity of SIS cryogels on NP cells and found that NP cells seeded on the SIS cryogel maintained proliferation and a high level of viability during the experiment duration, suggesting that this SIS cryogel has excellent cytocompatibility. This result is consistent with our previous experience and previous studies $[44,45]$.

Under physiological conditions, disc NP cells are subjected to various types of mechanical compression [17]. Previous studies and our own investigations have demonstrated that mechanical compression has an important role in regulating disc NP cell biology [18-21]. To investigate effects of mechanical compression on the matrix production of 3D-cultured NP cells, we analyzed for the first time the expression of NP cell-specific markers (keratin-19, FOXF1 and PAX1) under mechanical compression. Generally, the expression of these NP cell-specific markers was higher in the dynamic compression group than that in the static 


\section{Cellular Physiology Cell Physiol Biochem 2018;46:482-491 \begin{tabular}{l|l} 
and Biochemistry Published online: April 03, 2018 & $\begin{array}{l}\text { DO } 2018 \text { The Author(s). Published by S. Karger AG, Basel } \\
\text { www.karger.com/cpb }\end{array}$ \\
\hline
\end{tabular} \\ Xu et al.: Dynamic Compression Promotes the Matrix Synthesis of NP Cells}

compression group, indicating that dynamic compression is beneficial to maintaining a normal NP cell phenotype compared with the ability of static compression to maintain the desired phenotype. Maintenance of a normal NP cell phenotype is important for synthesizing and secreting a native tissue extracellular matrix. Collagen and proteoglycan are the main macromolecules within the NP matrix [41]. Here, dynamic compression also promoted the gene and protein expression of the NP matrix molecules (aggrecan and collagen II) compared with the expression levels in the cells under static compression, indicating that dynamic compression is helpful to promote the matrix biosynthesis of NP cells compared with the ability of static compression to do so. In line with this, several previous studies demonstrated that dynamic compression is more helpful than static compression in maintaining a healthy disc biology $[11,23,46]$.

$\mathrm{N}-\mathrm{CDH}$-mediated signaling is helpful to maintain a normal NP cell phenotype and NP matrix synthesis in vitro $[29,30]$. In this study, N-CDH up-regulation coincided with better maintenance of the NP cell phenotype and NP matrix synthesis in the dynamic compression group. However, N-CDH knockdown decreased the expression of NP cell-specific markers (keratin-19, FOXF1 and PAX1) and NP matrix macromolecules (aggrecan and collagen II) under dynamic compression, indicating that $\mathrm{N}-\mathrm{CDH}$ up-regulation may be responsible for the positive effects of dynamic compression on the maintenance of the NP cell phenotype and NP matrix biosynthesis. Moreover, N-CDH knockdown decreased the activity of the PI3K/Akt pathway in the cells under dynamic compression, whereas inhibition of the PI3K/ Akt pathway did not affect N-CDH expression but attenuated the maintenance of the NP cell phenotype and NP matrix synthesis under dynamic compression, further indicating that $\mathrm{N}-\mathrm{CDH}$ sustains the NP cell phenotype and matrix biosynthesis through activating the PI3K/ Akt pathway under dynamic compression.

This study also has several limitations. First, though we evaluated the effects of mechanical compression on the matrix synthesis of 3D-cultured NP cells, an in vivo animal model was not performed due to the difficulty in developing a device that can accurately apply dynamic compression to IVDs in vivo. Second, an in vivo animal repair model may be more helpful to investigate the efficacy of this kind of tissue-engineered NP tissue in regenerating degenerate discs after it is matured under dynamic compression stimulation. In the future, we will plan to perform an in vivo animal experiment to verify this point.

In conclusion, we studied the effects and potential mechanism of mechanical compression on the matrix production of 3D-cultured NP cells in vitro. Based on our findings, we demonstrate that dynamic compression can promote matrix biosynthesis in 3D-cultured $\mathrm{NP}$ cells in vitro through regulating the N-CDH-PI3K/Akt pathway.

\section{Disclosure Statement}

The authors do not have any conflicts of interest related to this work.

\section{References}

1 Silva-Correia J, Correia SI, Oliveira JM, Reis RL: Tissue engineering strategies applied in the regeneration of the human intervertebral disk. Biotechnol Adv 2013;31:1514-1531.

-2 Tong W, Lu Z, Qin L, Mauck RL, Smith HE, Smith LJ, Malhotra NR, Heyworth MF, Caldera F, EnomotoIwamoto M, Zhang Y: Cell therapy for the degenerating intervertebral disc. Transl Res 2016;S19315244(16)30403-0 [pii]. 10.1016/j.trsl.2016.11.008 [doi]

3 Henry N, Colombier P, Lescaudron L, Hamel O, Le Bideau J, Guicheux J, Clouet J: [Regenerative medicine of the intervertebral disc: from pathophysiology to clinical application]. Med Sci (Paris) 2014;30:1091-1100.

4 Ma JF, Zang LN, Xi YM, Yang WJ, Zou D: MiR-125a Rs12976445 Polymorphism is Associated with the Apoptosis Status of Nucleus Pulposus Cells and the Risk of Intervertebral Disc Degeneration. Cell Physiol Biochem 2016;38:295-305. 


\section{Cellular Physiology Cell Physiol Biochem 2018;46:482-491 \begin{tabular}{l|l} 
and Biochemistry Published online: April 03, 2018 & $\begin{array}{l}\text { D) } 2018 \text { The Author(s). Published by S. Karger AG, Basel } \\
\text { www.karger.com/cpb }\end{array}$ \\
\hline Xut.
\end{tabular} \\ Xu et al.: Dynamic Compression Promotes the Matrix Synthesis of NP Cells}

5 Yang Q Xu HW, Hurday S, Xu BS: Construction Strategy and Progress of Whole Intervertebral Disc Tissue Engineering. Orthop Surg 2016;8:11-18.

6 Yang Q Zhao YH, Xia Q, Xu BS, Ma XL, Liu Y, Hu YC, Li HF, Miao J, Wang T, Ma JX, Sun XL: Novel cartilagederived biomimetic scaffold for human nucleus pulposus regeneration: a promising therapeutic strategy for symptomatic degenerative disc diseases. Orthop Surg 2013;5:60-63.

7 Xu B, Xu H, Wu Y, Li X, Zhang Y, Ma X, Yang Q: Intervertebral Disc Tissue Engineering with Natural Extracellular Matrix-Derived Biphasic Composite Scaffolds. PLoS One 2015;10:e0124774.

-8 O’Connell GD, Leach JK, Klineberg EO: Tissue Engineering a Biological Repair Strategy for Lumbar Disc Herniation. Biores Open Access 2015;4:431-445.

-9 Li P, Xu Y, Gan Y, Wang L, Ouyang B, Zhang C, Luo L, Zhao C, Zhou Q: Estrogen Enhances Matrix Synthesis in Nucleus Pulposus Cell through the Estrogen Receptor beta-p38 MAPK Pathway. Cell Physiol Biochem 2016;39:2216-2226.

10 Hayes AJ, Benjamin M, Ralphs JR: Extracellular matrix in development of the intervertebral disc. Matrix Biol 2001;20:107-121.

11 Setton LA, Chen J: Mechanobiology of the intervertebral disc and relevance to disc degeneration. J Bone Joint Surg Am 2006;88 Suppl 2:52-57.

12 Pearce RH, Grimmer BJ, Adams ME: Degeneration and the chemical composition of the human lumbar intervertebral disc. J Orthop Res 1987;5:198-205.

13 Wang SZ, Rui YF, Lu J, Wang C: Cell and molecular biology of intervertebral disc degeneration: current understanding and implications for potential therapeutic strategies. Cell Prolif 2014;47:381-390.

14 Urban JP: The role of the physicochemical environment in determining disc cell behaviour. Biochem Soc Trans 2002;30:858-864.

15 Yang X, Li X: Nucleus pulposus tissue engineering: a brief review. Eur Spine J 2009;18:1564-1572.

-16 O'Halloran DM, Pandit AS: Tissue-engineering approach to regenerating the intervertebral disc. Tissue Eng 2007;13:1927-1954.

17 Hwang D, Gabai AS, Yu M, Yew AG, Hsieh AH: Role of load history in intervertebral disc mechanics and intradiscal pressure generation. Biomech Model Mechanobiol 2012;11:95-106.

18 Li P, Gan Y, Wang H, Xu Y, Song L, Zhang C, Li S, Zhou Q: Biological Responses of the Immature Annulus Fibrosus to Dynamic Compression in a Disc Perfusion Culture. Cells Tissues Organs 2016;10.1159/000446363

19 Li P, Gan Y, Wang H, Zhang C, Wang L, Xu Y, Song L, Li S, Li S, Ou Y, Zhou Q: Dynamic Compression Effects on Immature Nucleus Pulposus: a Study Using a Novel Intelligent and Mechanically Active Bioreactor. Int J Med Sci 2016;13:225-234.

20 Li P, Gan Y, Xu Y, Song L, Wang H, Zhang C, Wang L, Zhao C, Luo L, Zhou Q: Matrix homeostasis within the immature annulus fibrosus depends on the frequency of dynamic compression: a study based on the selfdeveloped mechanically active bioreactor. Biomech Model Mechanobiol 2016;10.1007/s10237-016-08230

-21 Neidlinger-Wilke C, Galbusera F, Pratsinis H, Mavrogonatou E, Mietsch A, Kletsas D, Wilke HJ: Mechanical loading of the intervertebral disc: from the macroscopic to the cellular level. Eur Spine J 2014;23 Suppl 3:S333-343.

-22 van der Veen AJ, van Dieen JH, Nadort A, Stam B, Smit TH: Intervertebral disc recovery after dynamic or static loading in vitro: is there a role for the endplate? J Biomech 2007;40:2230-2235.

23 Wang DL, Jiang SD, Dai LY: Biologic response of the intervertebral disc to static and dynamic compression in vitro. Spine (Phila Pa 1976) 2007;32:2521-2528.

24 Walsh AJ, Lotz JC: Biological response of the intervertebral disc to dynamic loading. J Biomech 2004;37:329-337.

25 Bruses JL: N-cadherin signaling in synapse formation and neuronal physiology. Mol Neurobiol 2006;33:237-252.

-26 Halbleib JM, Nelson WJ: Cadherins in development: cell adhesion, sorting, and tissue morphogenesis. Genes Dev 2006;20:3199-3214.

-27 Lv F, Leung VY, Huang S, Huang Y, Sun Y, Cheung KM: In search of nucleus pulposus-specific molecular markers. Rheumatology (Oxford) 2014;53:600-610. 


\section{Cellular Physiology Cell Physiol Biochem 2018;46:482-491 \begin{tabular}{l|l} 
and Biochemistry Published online: April 03, 2018 & $\begin{array}{l}\text { (c) } 2018 \text { The Author(s). Published by S. Karger AG, Basel } \\
\text { www.karger.com/cpb }\end{array}$
\end{tabular} \\ Xu et al.: Dynamic Compression Promotes the Matrix Synthesis of NP Cells}

28 Minogue BM, Richardson SM, Zeef LA, Freemont AJ, Hoyland JA: Transcriptional profiling of bovine intervertebral disc cells: implications for identification of normal and degenerate human intervertebral disc cell phenotypes. Arthritis Res Ther 2010;12:R22.

29 Hwang PY, Jing L, Chen J, Lim FL, Tang R, Choi H, Cheung KM, Risbud MV, Gersbach CA, Guilak F, Leung VY, Setton LA: N-cadherin is Key to Expression of the Nucleus Pulposus Cell Phenotype under Selective Substrate Culture Conditions. Sci Rep 2016;6:28038.

-30 Hwang PY, Jing L, Michael KW, Richardson WJ, Chen J, Setton LA: N-Cadherin-Mediated Signaling Regulates Cell Phenotype for Nucleus Pulposus Cells of the Intervertebral Disc. Cell Mol Bioeng 2015;8:51-62.

-31 Li P, Liang Z, Hou G, Song L, Zhang R, Gan Y, Zhang C, Xu Y, Zhou Q: N-Cadherin-Mediated Activation of PI3K/Akt-GSK-3beta Signaling Attenuates Nucleus Pulposus Cell Apoptosis Under High-Magnitude Compression. Cell Physiol Biochem 2017;44:229-239.

32 Wang Z, Leng J, Zhao Y, Yu D, Xu F, Song Q Qu Z, Zhuang X, Liu Y: N-Cadherin Maintains the Healthy Biology of Nucleus Pulposus Cells under High-Magnitude Compression. Cell Physiol Biochem 2017;43:2327-2337.

-33 Rutges J, Creemers LB, Dhert W, Milz S, Sakai D, Mochida J, Alini M, Grad S: Variations in gene and protein expression in human nucleus pulposus in comparison with annulus fibrosus and cartilage cells: potential associations with aging and degeneration. Osteoarthritis Cartilage 2010;18:416-423.

34 Rajpurohit R, Risbud MV, Ducheyne P, Vresilovic EJ, Shapiro IM: Phenotypic characteristics of the nucleus pulposus: expression of hypoxia inducing factor-1, glucose transporter-1 and MMP-2. Cell Tissue Res 2002;308:401-407.

-35 Minogue BM, Richardson SM, Zeef LA, Freemont AJ, Hoyland JA: Characterization of the human nucleus pulposus cell phenotype and evaluation of novel marker gene expression to define adult stem cell differentiation. Arthritis Rheum 2010;62:3695-3705.

-36 Urban JP, Roberts S: Degeneration of the intervertebral disc. Arthritis Res Ther 2003;5:120-130.

-37 Wang F, Cai F, Shi R, Wang XH, Wu XT: Aging and age related stresses: a senescence mechanism of intervertebral disc degeneration. Osteoarthritis Cartilage 2016;24:398-408.

-38 Zhao CQ, Wang LM, Jiang LS, Dai LY: The cell biology of intervertebral disc aging and degeneration. Ageing Res Rev 2007;6:247-261.

-39 Ghannam M, Jumah F, Mansour S, Samara A, Alkhdour S, Alzuabi MA, Aker L, Adeeb N, Massengale J, Oskouian R, Tubbs RS: Surgical anatomy, radiological features, and molecular biology of the lumbar intervertebral discs. Clin Anat 2016;10.1002/ca.22822 [doi]

40 Priyadarshani P, Li Y, Yao L: Advances in biological therapy for nucleus pulposus regeneration. Osteoarthritis Cartilage 2016;24:206-212.

41 Hsieh AH, Twomey JD: Cellular mechanobiology of the intervertebral disc: new directions and approaches. J Biomech 2010;43:137-145.

42 Vedicherla S, Buckley CT: Cell-based therapies for intervertebral disc and cartilage regeneration - current concepts, parallels and perspectives. J Orthop Res 2016;10.1002/jor.23268 [doi]

43 Vadala G, Russo F, Ambrosio L, Loppini M, Denaro V: Stem cells sources for intervertebral disc regeneration. World J Stem Cells 2016;8:185-201.

-44 Kim SH, Song JE, Lee D, Khang G: Development of poly(lactide-co-glycolide) scaffold-impregnated small intestinal submucosa with pores that stimulate extracellular matrix production in disc regeneration. J Tissue Eng Regen Med 2014;8:279-290.

45 Mercuri JJ, Gill SS, Simionescu DT: Novel tissue-derived biomimetic scaffold for regenerating the human nucleus pulposus. J Biomed Mater Res A 2011;96:422-435.

-46 Chan SC, Ferguson SJ, Gantenbein-Ritter B: The effects of dynamic loading on the intervertebral disc. Eur Spine J 2011;20:1796-1812. 